This item was submitted to Loughborough's Research Repository by the author.

Items in Figshare are protected by copyright, with all rights reserved, unless otherwise indicated.

\title{
Barriers to addressing sustainable construction in public procurement strategies
}

\section{PLEASE CITE THE PUBLISHED VERSION}

http://dx.doi.org/10.1680/ensu.2011.164.4.229

\section{PUBLISHER}

(c) ICE Publishing Ltd.

VERSION

VoR (Version of Record)

LICENCE

CC BY-NC-ND 4.0

\section{REPOSITORY RECORD}

Sourani, Amr, and M. Sohail. 2019. "Barriers to Addressing Sustainable Construction in Public Procurement Strategies". figshare. https://hdl.handle.net/2134/9315. 
This item was submitted to Loughborough's Institutional Repository (https://dspace.lboro.ac.uk/) by the author and is made available under the following Creative Commons Licence conditions.

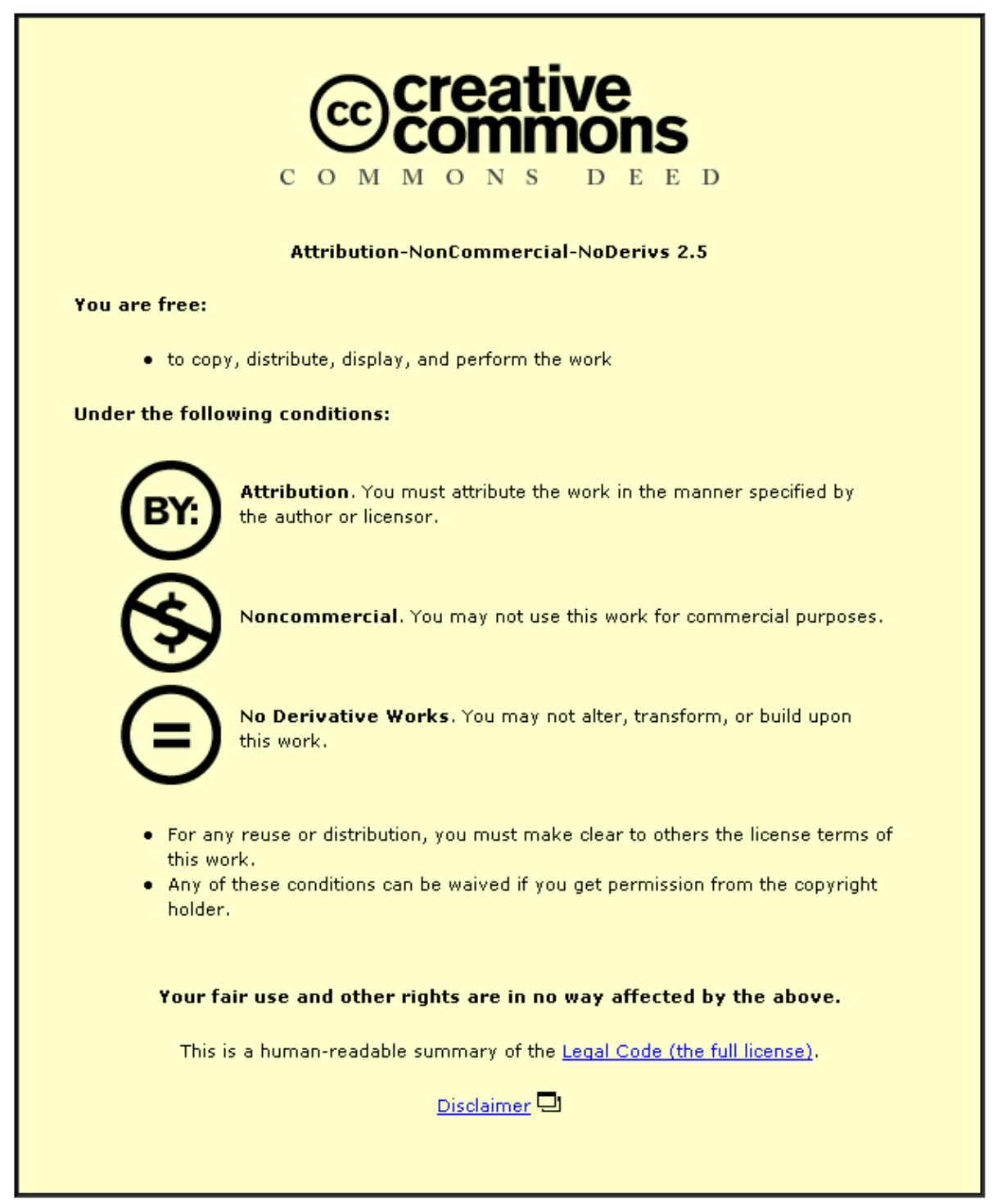

For the full text of this licence, please go to: http://creativecommons.org/licenses/by-nc-nd/2.5/ 
Engineering Sustainability

Volume 164 Issue ES4

Barriers to addressing sustainable

construction in public procurement

strategies

Sourani and Sohail

ice proceedings
Proceedings of the Institution of Civil Engineers

Engineering Sustainability 164 December 2011 Issue ES4

Pages 229-237 http://dx.doi.org/10.1680/ensu.2011.164.4.229

Paper 900034

Received 23/06/2009 Accepted 19/11/2010

Keywords: procurement/public policy/sustainability

\section{Barriers to addressing sustainable construction in public procurement strategies}

1 Amr Sourani MSc, PhD

Senior Lecturer in Construction Management, School of the Built Environment, Liverpool John Moores University, UK
2 Muhammad Sohail MSc, PhD, Fellow, ASCE

Professor of Sustainable Infrastructure, Director of Research and Enterprise (WEDC), Department of Civil and Building Engineering, Loughborough University, UK
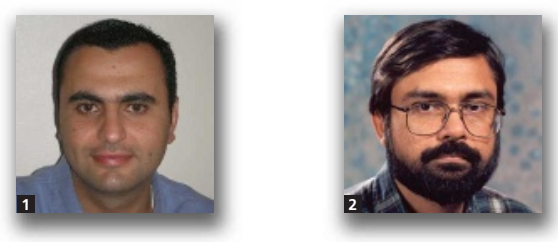

There is an increasing demand on public clients in the UK to address sustainability in construction procurement. This paper presents the results of an investigation into the barriers facing these clients in attempting to address sustainable construction in procurement strategies and the parties most capable of removing such barriers. The investigation draws on interviews conducted with sustainability professionals and experts working in a variety of professional and public sector organisations in the UK. Twelve main barriers were identified, namely: lack of funding, restrictions on expenditure and reluctance to incur higher capital cost when needed; lack of awareness, understanding, information, commitment and demand; insufficient/inconsistent policies, regulations, incentives and commitment by leadership; insufficient/confusing guidance, tools, demonstrations and best practice; vagueness of definitions and diversity of interpretations; separation between capital budget and operational budget; lack of sufficient time to address sustainability issues; lack of long-term perspective; general perception that addressing sustainability always leads to incurring greater capital cost; resistance to change; insufficient integration and link-up in the industry; and insufficient research and development. Four parties were identified as the those most capable of removing the barriers, namely: government (including regulatory bodies); professional/educational bodies; the supply chain; and users.

\section{Introduction}

The public sector accounts for $40 \%$ of the gross domestic product of the UK and employs around a quarter of the UK workforce (OGC, 2005a). This sector encompasses several organisations and departments, including central civil government departments and agencies, the National Health Service (NHS) and its local trusts, the Ministry of Defence, Northern Ireland Assembly, National Assembly for Wales and Scottish Executive, local authorities, universities and colleges.

Construction in the public sector includes a wide range of activities comprising major infrastructure and civil engineering projects, major building programmes (such as hospitals, schools, prisons and social housing), in addition to refurbishment and maintenance activities. While all government bodies are involved in construction activities, the involvement of these bodies can range from engaging in construction as a core business for some bodies (as in the case of the Highways Agency) to occasional involvement of other bodies in significant construction projects (for example every 20 or 30 years). Most of the government bodies, however, undertake repair and maintenance programmes (NAO, 2005a).

Sustainable construction is about achieving a balance between the social, economic and environmental aspects of construction so that the costs and the benefits, evaluated along these three dimensions, are optimised. In the light of the huge expenditure of the UK public sector on construction (which, according to Cridland et al. (2010), represents about $40 \%$ of the industry's turnover), the benefits that can be gained from integrating 
Engineering Sustainability

Volume 164 Issue ES4
Barriers to addressing

sustainable construction in

public procurement strategies

Sourani and Sohail sustainability into construction procurement can be very significant. In line with this was the production of several governmental reports calling on UK public clients to address sustainable construction in procurement strategies. However, attempts made by public procurers to respond to such demands have been hindered by several barriers. The aim of this paper is to present the results of an investigation into

(a) the barriers facing UK public clients in attempting to better address sustainable construction in developing procurement strategies

(b) the parties most capable of removing such barriers.

\section{Sustainable development}

Sustainable development has become an increasingly important topic at the global level. It was declared as an overarching policy goal by governments represented at the Earth Summit on Development and Environment (Parkin et al., 2003). Given the increasing recognition of the concept, more than 200 definitions of sustainable development exist. Possibly the best known definition is the one introduced by the World Commission on Environment and Development (WCED, 1987)

Humanity has the ability to make development sustainable-to ensure that it meets the needs of the present without compromising the ability of future generations to meet their own needs. The concept of sustainable development does imply limits-not absolute limits but limitations imposed by the present state of technology and social organization on environmental resources and by the ability of the biosphere to absorb the effects of human activity...

Sustainable construction, in general, refers to the application of the principles of sustainable development to the construction industry. Sustainable construction encompasses several dimensions which, at least, involve the following

(a) social dimension: focusing on issues such as health and safety, involvement of stakeholders, equality and diversity in the workplace and creating employment opportunities

(b) economic dimension: focusing on issues such as whole life costing, support of local economies and financial affordability for intended beneficiaries

(c) environmental dimension: focusing on issues such as reducing energy and water consumption, using renewable resources and minimising pollution.

Some publications have mentioned other dimensions of sustainability such as technical sustainability (Ashley et al., 2003; Hill and Bowen, 1997), cultural sustainability (CIB, 1999; Langford et al., 1999; Ofori, 1998), community sustainability and managerial sustainability (Ofori, 1998). However, in the context of the UK construction industry, the concept of the triple bottom line, which focuses on social, economic and environmental sustainability, remains dominant.

\section{Sustainable procurement in the UK context}

Official reports published in the UK have reflected the increasing emphasis on sustainable procurement. Examples include publications by the Strategic Forum for Construction (2002), the Department of the Environment, Transport and the Regions (DETR, 2000), the Rethinking Construction's Respect for People Working Group (2002) and the Office of Government Commerce (OGC, 2005b). In 2007, the government published the Sustainable Procurement Action Plan (Defra, 2007). Among the goals set in the plan was for the UK to be 'among the European Union (EU) leaders in sustainable procurement by 2009' and to achieve 'a low carbon, more resource-efficient public sector' (Defra, 2007, p. 3). The plan described targets in detail and specified how the government would achieve them.

In June 2008, a joint industry-government strategy for sustainable construction was launched (HM Government and Strategic Forum for Construction, 2008). The strategy has been agreed across government and covers both buildings and infrastructure. The strategy aims to provide clarity around the existing policy framework and the range of commitments, targets and actions relevant to sustainable construction (Ciria, 2008; HM Government and Strategic Forum for Construction, 2008). A set of overarching targets has been presented to deliver the strategy. These targets are related to both the ends of sustainable construction (which relate directly to sustainability issues, e.g. biodiversity) and the means of sustainable construction (i.e. the processes helping to achieve those ends). Among these are six targets representing the ends (including climate change mitigation, climate change adaptation, water, biodiversity, waste and materials) and five targets representing the means (including procurement, design, innovation, people and better regulation). According to the strategy, the overarching target of procurement is to

achieve improved whole life value through the promotion of best practice construction procurement and supply side integration, by encouraging the adoption of the Construction Commitments ... in both the public and private sectors and throughout the supply chain (HM Government and Strategic Forum for Construction, 2008, p. 7).

According to OGC (2003, p. 2), the procurement strategy

identifies the best way of achieving the objectives of the project and value for money, taking account of the risks and constraints, leading to decisions about the funding mechanism and asset ownership for the project. The aim of a procurement strategy is to 
Engineering Sustainability

Volume 164 Issue ES4
Barriers to addressing

sustainable construction in

public procurement strategies

Sourani and Sohail achieve the optimum balance of risk, control and funding for a particular project.

In the context of public procurement in the UK, key tasks in developing a procurement strategy include: producing an outline business case, determining procurement route (including contract strategy), producing output-based specification and criteria for selection and award and placing an advertisement in the Official Journal of the European Union (OJEU) if required (OGC, 2003). The importance of considering sustainability at the stage of developing a procurement strategy has been highlighted in several publications. Examples are listed below.

- The Improvement and Development Agency (IDeA, 2003, p. 3) shows that

the key opportunity to consider environmental and social issues is at the earliest stages of the procurement cycle: identifying needs and building them into the design or specification. Adverse impacts should be managed out at this point.

- The then Office of the Deputy Prime Minister (ODPM, 2003 , p. 50), in establishing how to achieve community benefits through procurement, provides the following recommendation:

implement sustainable design and sustainable procurement strategies and build sustainability into procurement processes and contracts, where relevant to contract. Sustainability in design (buildings, infrastructure, urban, green spaces, products) and procurement should be addressed in risk-based strategies that complement the corporate procurement strategy and the community plan. Include environmental requirements in the user needs and specification at the earliest stages of the procurement process.

- OGC (2005b) shows that the project brief, as part of the procurement process, must highlight the importance of sustainability and that the client must include sustainable performance objectives in the specification to enable tenderers to respond to these objectives.

Despite the production of several publications by governmental departments and professional organisations to address the subject of sustainable construction procurement, there was a lack of evidence-based research into the barriers to better address sustainable construction by UK public clients in developing a procurement strategy and the parties most capable to remove these barriers. Identifying these barriers and parties is at the heart of this paper.

\section{Research methodology}

The investigation presented in this paper is part of a research project that aimed at developing a theoretical framework to assist public clients in addressing sustainable construction in procurement strategies. The research design for this investigation is part of an overall research design for the whole research project, which involved a Delphi exercise, interviews, questionnaire survey and case studies. However, as the scope of this paper is limited to presenting the results regarding the barriers and the parties most capable of removing them, the discussion presented below relates only to the methods and strategies used in the identification of these barriers and parties.

Interviews were seen as a suitable method to adopt, for reasons related to the nature of information sought, flexibility and the potential of clarifying the meaning and the objectives of the questions (Bryman and Bell, 2003; Jankowicz, 1991; Sekaran, 2003). Two sets of interviews with sustainability professionals and experts were conducted. The first set comprised interviews conducted with nine professionals and experts working in a variety of leading professional and public sector organisations. The second set involved three interviews with professionals and experts as part of case studies about organisations demonstrating good practice of sustainable procurement. All interviews carried out were of a semi-structured nature. This type of interview was adopted because a fairly clear focus on the issues to be addressed was available and a list of possible questions was already established. Moreover, issues such as obtaining the respondents' views concerning what was important in explaining and understanding the problem and the provision of flexibility to achieve this were important considerations.

Knowledge in the field of sustainable construction procurement was the key criterion to consider for selecting the experts and the professionals who were interviewed. Several indicators of such knowledge, as highlighted by several authors (Henchion and McIntyre, 2005; Khosrow-Pour and Herman, 2001; Martino, 1983; Scholl et al., 2004; Shon and Swatman, 1998) were considered. Among these indicators are

- publications in the field

- signs of professionals' eminence such as leadership, membership, or holding office in a professional society or organisation

- peer judgment and recommendations

- honours by professional societies

- self-rating of the expertise in the relevant area

- presentations made at national conventions

- relevant years of experience.

Before conducting the interviews, the interviewees were informed about the research project, its aims and the time needed to complete an interview. An interview guide was sent 
Engineering Sustainability

Volume 164 Issue ES4
Barriers to addressing

sustainable construction in

public procurement strategies

Sourani and Sohail to interviewees before the interviews were conducted. The guide included definitions and clarifications regarding terms such as 'sustainable development,' 'sustainable construction' and 'procurement strategies,' to ensure that all such terms were interpreted by the interviewees in the same way. The interviewees were sent the interview questions in advance of conducting the interview. These included open-ended questions about the barriers to better addressing sustainable construction in developing construction projects' procurement strategies and about the parties who are most capable of removing these barriers. The interview questions also included other questions which lie outside the scope of this paper. The interviews, which were carried out either face-to-face or over the telephone, were recorded, after obtaining the interviewees' permission. The recorded interviews were transcribed and analysed. The analysis led to the identification of 12 barriers of composite nature, as well as four main parties most capable of removing the barriers. Coding, a key process in most qualitative data analysis strategies (Bryman and Bell, 2003), was used in analysing the data. The analysis process involved the following steps:

- reading and re-reading the responses received

- establishing preliminary categories within which the responses could be classified; such categories emerged from key words used in the responses and from the words or phrases that were frequently used in the responses (in establishing the categories, the need to use the best exemplifying phrases was also taken into account)

- coding the responses within the established categories

- reviewing the categories formulated and the responses classified to ensure that the responses were classified appropriately and to identify the possibility of modifying the categories formulated, for example by merging similar categories

- reviewing the modified categories to ensure the appropriateness of the undertaken coding.

While every effort was made to ensure that an appropriate coding was used and that the categories formulated provided an appropriate representation of the responses, it is important to note that other classifications of the responses may exist.

\section{Findings and discussion}

\subsection{Barriers}

The main findings regarding the barriers are categorised into 12 main barriers of composite nature. These comprise the following:

(a) lack of funding, restrictions on expenditure and reluctance to incur higher capital cost when needed (b) lack of awareness, understanding, information, commitment and demand

(c) insufficient/inconsistent policies, regulations, incentives and commitment by leadership

(d) insufficient/confusing guidance, tools, demonstrations and best practice

(e) vagueness of definitions and diversity of interpretations

(f) separation between capital budget and operational budget

( $g$ ) lack of sufficient time to address sustainability issues

(h) lack of long-term perspective

(i) general perception that addressing sustainability always leads to incurring greater capital cost

(j) resistance to change

(k) insufficient integration and link-up in the industry

(l) insufficient research and development.

The barriers identified are discussed below.

\subsubsection{Lack of funding, restrictions on expenditure and reluctance to incur higher capital cost when needed}

This barrier was mentioned by nine out of the 12 interviewees ( $75 \%$ of the interviewees). The reduction of the funding available for public sector organisations and the imposition of restrictions on their expenditure is a major problem facing public clients in their attempts to obtain a more sustainable outcome. Moreover, in local authorities, for example, decisions should be justified to financial auditors who may not be accustomed to looking beyond managing the budget and may not be able to understand the need to take a sustainable route or appreciate the value that can be obtained by taking such a route; hence they may not be able to appreciate the need for more initial capital expenditure. The present authors have not come across any initiative to educate auditors on issues of long-term sustainability. It is assumed that the current financial audit practices will be sufficient for sustainable construction as well.

The financial problems mentioned above may exert more pressure on public clients to adopt the lowest cost option rather than best value and could be used by some as an excuse for not addressing sustainability issues in procurement strategies. These problems could also represent a constraint to investing in more sustainable solutions, particularly where more initial capital expenditure is required to address sustainability. Even if the party responsible for the capital budget is the same party responsible for the operational budget and can obtain the benefits of investing in sustainability solutions (the issue of separation between capital and operational budgets is discussed later in this paper), such a party may not be able to bear higher capital cost, particularly if that party was under financial pressure. This supports the findings of NAO (2005b), which reported that the conflict between 
Engineering Sustainability

Volume 164 Issue ES4
Barriers to addressing

sustainable construction in

public procurement strategies

Sourani and Sohail sustainable procurement and reducing costs was one of the barriers to sustainable procurement in central government.

\subsubsection{Lack of awareness, understanding, information, commitment and demand}

This barrier was mentioned by seven out of the 12 interviewees $(58 \%)$. The results obtained highlighted that the low level of awareness and understanding about sustainability issues not only exists among people working in public client organisations (including senior procurement decision-makers) but also among other stakeholders' organisations and groups (such as contractors, funding organisations and users). Some of these stakeholders may not stimulate levels of demand that are sufficient to advance the agenda beyond minimum compliance with regulations. This may be attributed to the lack of training on sustainable development issues in the several institutions and professional bodies, the lack of long-term perspective, the confusion created by the several interpretations and indicators, the lack of clear and structured guidance and the nature of the relevant codes in terms of being advisory rather than mandatory. The results obtained also highlighted the lack of information needed to make the right decisions in relation to issues such as selection of sustainable products and materials (e.g. how the materials were obtained, the embodied energy, the recycled content, etc.). Such results support the findings of NAO (2005b), which reported lack of knowledge about what sustainable procurement is and how to achieve it as one of the main barriers to sustainable procurement in central government.

\subsubsection{Insufficient/inconsistent policies, regulations, incentives and commitment by leadership}

This barrier was mentioned by seven interviewees (58\%). The policies, regulations, incentives and commitment by leadership may not be sufficient to move towards realisation of sustainable development. Examples highlighted by the interviewees in relation to this included the lack of sufficient funds allocated for government departments and the restrictions imposed by the Treasury on expenditure. These could obstruct long-term thinking by public sector organisations and could hinder their efforts to invest in sustainability measures. One of the interviewees provided another relevant example that is related to value added tax (VAT) imposed on refurbishment. Despite the recognition that refurbishment could be a better option than new build from an environmental point of view, there is a question about why refurbishment is penalised by imposing a VAT on it, while no VAT is imposed on new build. Another example mentioned was the inconsistency of having a policy requirement for local authorities to make annual savings of $2.5 \%$ and at the same time having a requirement to integrate sustainability issues within procurement by local authorities (an issue that could lead to incurring greater capital cost).
Although there are regulations and government policies in place to assist in addressing sustainability issues in public procurement (e.g. Part L of the building regulations, European Union energy performance building directive, the code for sustainable buildings, planning and policy statement 22 (PPS 22), the strategy for sustainable construction), such regulations and policies may be insufficient. During the interviews conducted, several interviewees supported this view. In particular, they highlighted that in the current situation, the incorporation of some sustainability issues remains optional. There is a need therefore for a more mandatory role in order to better address sustainability.

One important issue to note when examining the appropriateness of current legislation in relation to considering sustainability is how advanced the position of the organisation is in terms of addressing the sustainability agenda. While there is scope to do more by most bodies within the existing legislation, this legislation may be seen restrictive to certain organisations, such as the Environment Agency or the London Borough of Camden. These organisations already have high standards of sustainable procurement and wish to do more, particularly in relation to social issues (Environmental Audit Committee, 2005). The views regarding the need for stronger government policies are supported by the existing literature. For example, the Sustainable Housing Forum and the World Wide Fund for Nature (TCPA and WWF, 2003) highlighted the need for backing the construction industry by strong planning policies requiring developers to build strong sustainability credentials into new developments. The views expressed by the Environmental Audit Committee (2005) also seem to be supportive in this regard. The committee showed that there was an opportunity for the central government to set out its expectations through stronger policy messages. Furthermore, lack of leadership on sustainable procurement was suggested by NAO (2005b) as a main barrier to sustainable procurement in central government.

\subsubsection{Insufficient/confusing guidance, tools, demonstrations and best practice}

This barrier was mentioned by six interviewees (50\%). Although there are tools and indicators already in place (e.g. Building Research Establishment Environmental Assessment Method (Breeam), key performance indicators (KPIs), 'respect for people' indicators), the huge number of these tools and indicators, without clarity on how and when to use them and by whom, is creating confusion and burden among practitioners. Moreover, these tools and indicators are not sufficiently comprehensive to assess the full range of sustainability criteria. There is a growing need to develop simple but comprehensive tools and techniques to deal with situations where sustainability needs to be assessed. For example, these can include a situation where an assessment of contractors' 
Engineering Sustainability

Volume 164 Issue ES4
Barriers to addressing

sustainable construction in

public procurement strategies

Sourani and Sohail performance on sustainability needs to be undertaken so that the results of such an assessment can be integrated in contractors' pre-qualification and selection procedures. The interviews also highlighted the lack of simple and structured guidance, demonstrations and best practice illustrating what is operationally meant by sustainability and how to implement it. Such findings support the views expressed by NAO (2005b), which highlighted the issue of how to achieve sustainable procurement as a main barrier.

\subsubsection{Vagueness of definitions and diversity of interpretations}

This barrier was mentioned by four interviewees $(33 \%)$. The results showed that the definitions of many of the issues related to sustainability were vague and confusing and that sustainability was interpreted differently by different people. For example, one of the interviewees highlighted the difficulty in making a clear distinction between whole life value, whole life costing and life cycle assessment. Vagueness of definitions and diversity of interpretations make it difficult to confine sustainability to anything in particular. This therefore may be used by some decision-makers as an excuse to ignore addressing sustainability issues.

\subsubsection{Separation between capital budget and operational budget}

This barrier was mentioned by four interviewees (33\%). Quite often, the organisation (or the part of the organisation) that is responsible and accountable for making the capital investment is not the same organisation (or the part of the organisation) that is responsible for the operational budget throughout the facility life cycle. In such a case, the organisation (or the part of the organisation) which is responsible for the capital investment might have no interest in investing in sustainable solutions (such as energy-saving measures) because it is not the same organisation (or the part of the organisation) that would reap the benefits achieved throughout the facility life cycle. As a result, the client, for example, may not be willing to develop more sustainability-oriented procurement strategies if this implies more investment and does not bring financial benefits to that client. Similarly, a contractor who does not have access to benefits that would be obtained as a result of having sustainable solutions in place may also be reluctant to invest in these solutions. The present authors have not observed any mechanism to develop a single node of accountability on issues related to sustainability of infrastructure.

\subsubsection{Lack of sufficient time to address sustainability issues}

This barrier was mentioned by four interviewees $(33 \%)$. Addressing the whole range of sustainability issues involves ensuring that a thorough appraisal of the social, economic and environmental dimensions underpinning sustainability has been undertaken. This is a lengthy process, which may require experts' advice. However, public clients do not often have sufficient time to undertake such a process. They may choose to ignore addressing sustainability requirements and to adopt practices that they are used to. Moreover, the results showed that public clients may find themselves in a situation where funding could be available for a limited period of time and therefore when designing and constructing a building, for example, they may not have sufficient time to address sustainability in an adequate way.

\subsubsection{Lack of long-term perspective}

This barrier was mentioned by four interviewees (33\%). As many of the benefits brought by sustainability are generally realised in the long term, several parties may not be able to see these benefits and therefore may have no interest in investing in sustainability. As the results obtained showed, the government, for example, may be in charge for a few years and therefore such a period would not be sufficient to realise many of the benefits brought by sustainability. As a result, government and politicians may be reluctant to invest in more sustainable solutions, favouring thereby their own short-term interests over the long-term interests of the wider society. The existence of a historical trend among public clients to choose the lowest cost, in addition to the lack of funding and the financial restrictions imposed on these clients could also be discouraging factors to the adoption of a long-term perspective. Some contractors also may not have a long-term perspective. Small contractors represent a large proportion of the industry and are constrained by very limited resources; therefore, they may not be able to look beyond their short-term interests. (The construction industry figures for GB show that around $90 \%$ of the firms are classified as micro, employing less than ten workers (Blake et al., 2004).)

\subsubsection{General perception that addressing sustainability always leads to incurring greater capital cost}

This barrier was mentioned by three interviewees $(25 \%)$. The results obtained showed that sustainability may require the incurrence of more capital cost, but this is not always the case. This is consistent with the literature; for example IDeA (2003) shows that there is mounting evidence that sustainable construction procurement does not necessarily result in an increased capital cost.

\subsubsection{Resistance to change}

This barrier was mentioned by two interviewees only $(17 \%)$. Sustainability requires new ways of thinking, methods, practices and attitude. Hence, it requires change. But as normally happens when implementing a new initiative; there is a resistance to change. This problem may exist at all levels; from client organisations, all the way through to the supply 
Engineering Sustainability

Volume 164 Issue ES4
Barriers to addressing

sustainable construction in

public procurement strategies

Sourani and Sohail side and funding organisations. In client organisations, the problem of change may be related to the lack of committed leadership, restrictions on funding and expenditure and the lack of clear guidance. In the supply side, the problem may be related to a passive culture, where no change would be initiated unless deemed necessary by the client. Such a problem could also be related to the limited nature of the resources possessed by small companies, which constitute a high proportion of the industry. For those involved in funding, the problem may be attributed to policies and practices that are directed towards reducing the initial cost and managing the budget rather than adopting a long-term perspective which addresses further social, economic and environmental implications. Unfortunately, the voluntary nature of the codes of practice can be seen by the different parties as an excuse for not initiating change in a sustainable direction.

\subsubsection{Insufficient integration and link-up in the industry}

This barrier was mentioned by two interviewees only $(17 \%)$. The lack of sufficient integration and link-up in the industry exists among clients and consultants, as well as the supply chain. Several opportunities for obtaining innovative and sustainable solutions could be missed due to the lack of coordination and link-up between the several parties involved in a construction project (e.g. with regard to integrating sustainability requirements within the design or the specification processes/stages).

\subsubsection{Insufficient research and development}

This barrier was mentioned by two interviewees only (17\%). Insufficient research and development could be attributed to lack of resources (mainly time and funding). The results obtained showed that although research was conducted to address the capital cost of the facilities, there was little work carried out regarding the facilities' operational costs, the relationship between the capital cost and the operational costs, or the measurement of the social costs and benefits associated with both the capital and operational costs.

\subsection{The way forward: the parties most capable of removing the barriers and needed actions}

Four key parties were identified as the parties who are most capable of removing the barriers presented above. These include:

(a) government (including regulatory bodies)

(b) professional/educational bodies

(c) the supply chain

(d) users.

The parties identified and their needed actions are discussed below.

\subsubsection{Government (including regulatory bodies)}

This party was mentioned by ten interviewees (83\%). Government (including regulatory bodies) should re-consider the consistency of objectives among financial restrictions imposed on public clients' spending, the agenda on sustainable construction and audit requirements, in order to put in place an appropriate incentive structure enabling the investment in sustainable solutions. Further attention should be given to producing simpler, more comprehensive and structured guidance, tools and techniques as well as demonstrations and best practice. Professional and higher education institutions in partnerships with the clients could develop a missing function of 'information/knowledge screening.' This is particularly true as many of the guides appear to be definitive (without much evidence base) and lack a third-party independent review. The scope of regulations should be extended to incorporate a wider range of sustainability issues criteria, such as those outlined in the OGC's guide Sustainability (OGC, 2005b). Public procurers could do a lot more than minimum compliance with legislation, regulations and government policies with regard to sustainability. Capacity development on sustainability issues at all levels has to be provided. Sufficient lead and preparation time has to be allowed in order to address sustainability. Communication and knowledge sharing have to be improved at inter- and intra-client organisation levels. Attention should be given to integrating sustainability within contractual procedures.

\subsubsection{Professional/educational bodies}

This party was mentioned by two interviewees only (17\%). Professional and educational bodies have an important role to play with regard to increasing the awareness of society as a whole in relation to sustainable development. As discussed previously, these bodies, in partnerships with the clients, could develop a missing function of 'information/knowledge screening.'

\subsubsection{The supply chain}

This party was mentioned by two interviewees only (17\%). Contractors should consider a more proactive approach together with the concept and the practices of corporate social responsibility. The supply chain as a whole should consider further integration within itself to enable construction firms to have a longer-term perspective. This could increase the likelihood of addressing sustainable construction issues, as many of the benefits brought by sustainability are normally realised over the long term.

\subsubsection{Users}

This party was mentioned by one interviewee only $(8 \%)$. To move the sustainable procurement agenda forward, demand by users (e.g. occupants of a facility) for sustainable products 
Engineering Sustainability

Volume 164 Issue ES4
Barriers to addressing

sustainable construction in

public procurement strategies

Sourani and Sohail should be stimulated (e.g. through introducing energy ratings to buildings).

\section{Conclusion}

In the light of the huge expenditure of the UK public sector on construction, the benefits (whether social, economic or environmental) that can be gained from integrating sustainability into construction procurement can be very significant. Public clients in the UK are coming under increasing demand to integrate sustainable construction in their procurement strategies. However, attempts made by public procurers to respond to such demands have been hindered by several barriers.

The investigation presented in this paper was based on interviews conducted with sustainability professionals and experts working in a variety of professional and public sector organisations. The results of the investigation highlighted 12 main barriers of composite nature. These included lack of funding, restrictions on expenditure and reluctance to incur higher capital cost when needed; lack of awareness, understanding, information, commitment and demand; insufficient/ inconsistent policies, regulations, incentives and commitment by leadership; insufficient/confusing guidance, tools, demonstrations and best practice; vagueness of definitions and diversity of interpretations; separation between capital budget and operational budget; lack of sufficient time to address sustainability issues; lack of long-term perspective; general perception that addressing sustainability always leads to incurring greater capital cost; resistance to change; insufficient integration and link-up in the industry; and insufficient research and development.

To move the sustainable procurement agenda forward several parties should act. Government (including regulatory bodies) is best placed to deal with financial, regulatory, policy and guidance obstacles. Individual public procurers should provide adequate training, sufficient time and appropriate communication. Professional and educational bodies should raise the level of awareness of sustainable development across the whole society. The supply chain should move towards further integration and users should stimulate demand on sustainable products.

\section{REFERENCES}

Ashley R, Blackwood D, Butler D et al. (2003) Sustainable decision making for the UK water industry. Proceedings of the Institution of Civil Engineers, Engineering Sustainability 156(1): 41-49.

Blake N, Croot J and Hastings J (2004) Measuring the Competitiveness of the UK Construction Industry - Volume 2. DTI, London. See http://www.bis.gov.uk/files/file19029. pdf for further details (accessed 8/04/2010).
Bryman A and Bell E (2003) Business Research Methods. Oxford University Press, New York.

CIB (International Council for Building) (1999) Agenda 21 on Sustainable Construction. Rotterdam, CIB, Rotterdam, CIB Report Publication 237.

CIRIA (Construction Industry Research and Information Association) (2008) See www.ciria.org.uk/cief/pdf/ 03_04_08_strategy_for_sustainable_construction_sw.pdf (accessed 1/10/2008).

Cridland J, Parker T, Beales R et al. (2010) Public Sector Construction Vital to Economy. See http://www.guardian. co.uk/business/2010/mar/05/public-sector-constructionvital-economy for further details (accessed 7/04/2010).

DEFRA (Department for Environment, Food and Rural Affairs) (2007) UK Government Sustainable Procurement Action Plan-Incorporating the Government Response to the Report of the Sustainable Procurement Task Force. DEFRA, London. See www.eauc.org.uk/file_uploads/ sustainableprocurementactionplan.pdf for further details (accessed 1/05/2009).

DETR (Department of the Environment, Transport and the Regions) (2000) Building a Better Quality of Life - A Strategy for More Sustainable Construction. DETR, London. See www.berr.gov.uk/files/file13547.pdf for further details (accessed 1/05/2009).

Environmental Audit Committee (2005) Sustainable Public Procurement Sixth Report of Session 2004-05. The Stationery Office, London, HC 266. See www.publications. parliament.uk/pa/cm200405/cmselect/cmenvaud/266/266. pdf for further details (accessed 2/05/2009.

Henchion M and McIntyre B (2005) Market access and competitiveness issues for food SMEs in Europe's lagging rural regions (LRRs). British Food Journal 107(6): 404-422.

Hill RC and Bowen PA (1997) Sustainable construction: Principles and a framework for attainment. Construction Management and Economics 15(3): 223-239.

HM Government and Strategic Forum for Construction (2008) Strategy for Sustainable Construction. Department for Business, Enterprise and Regulatory Reform, London. See www.berr.gov.uk/files/file46535.pdf (accessed 1/05/2009).

IDeA (Improvement and Development Agency) (2003) Sustainability and Local Government Procurement. IDeA, London. See www.idea.gov.uk/idk/aio/1701515 for further details (accessed 1/05/2009).

Jankowicz AD (1991) Business Research Projects for Students, 1st edn. Chapman and Hall, London.

Khosrow-Pour M and Herman N (2001) Critical issues of webenabled technologies in modern organizations. The Electronic Library 19(4): 208-220.

Langford DA, Zhang XQ, Macleod I and Dimitrijevic B (1999) Design and managing for sustainable building in the UK. Proceedings of the Profitable Partnering in Construction Procurement: CIB W92 (Procurement Systems) CIB TG 23 
Engineering Sustainability

Volume 164 Issue ES4
Barriers to addressing

sustainable construction in

public procurement strategies

Sourani and Sohail
(Culture in Construction) Joint Symposium (S. O. Ogunlana (ed.)), Chiang Mai, Thailand, pp. 373-382. E \& FN Spon, Oxford, UK.

Martino JP (1983) Technological Forecasting for Decision Making. Elsevier Science Publishing, New York.

NAO (National Audit Office) (2005a) Improving Public Services through Better Construction. The Stationery Office, London.

NAO (2005b) Sustainable Procurement in Central Government. NAO, London. See www.nao.org.uk/nao/psd_toolkit/ downloads.asp for further details (accessed 2/05/2009). ODPM (Office of the Deputy Prime Minister) (2003) National Procurement Strategy for Local Government. ODPM, London. See www.communities.gov.uk/publications/ localgovernment/nationalprocurementstrategy for further details (accessed 2/05/2009).

Ofori G (1998) Sustainable construction: principles and a framework for attainment - comment. Construction Management and Economics 16(2): 141-145.

OGC (Office of Government Commerce) (2003) Procurement Guide 06: Procurement and contract strategies. OGC, London. See www.ogc.gov.uk/documents/cp0066.pdf for further details (accessed 1/05/2009).

OGC (2005a) How Government Buys: Frequent Questions. OGC, London. See www.supplyinggovernment.gov.uk/faq.asp for further details (accessed 18/05/2005).

OGC (2005b) Procurement Guide 11: Sustainability. OGC, London.

Parkin S, Sommer F and Uren S (2003) Sustainable development: understanding the concept and practical challenge.
Proceedings of the Institution of Civil Engineers, Engineering Sustainability 156(1): 19-26.

Rethinking Construction's Respect for People Working Group (2002) Respect for People-A Framework for Action.

Rethinking Construction, London. See www.rcne.org.uk/ Documents/rfp_A_Framework_for_Action.pdf for further details (accessed 1/05/2009).

Scholl W, Konig C, Meyer B and Heising P (2004) The future of knowledge management: an international Delphi study. Journal of Knowledge Management 8(2): 19-35.

Sekaran U (2003) Research Methods for Business - A Skill Building Approach, 4th edn. Wiley, USA.

Shon T and Swatman PMC (1998) Identifying effectiveness criteria for Internet payment systems. Internet Research: Electronic Networking Applications and Policy 8(3): 202-218. Strategic Forum for Construction (2002) Accelerating Change A Report by the Strategic Forum for Construction Chaired by Sir John Egan. Rethinking Construction, London. See www.strategicforum.org.uk/pdf/report_sept02.pdf for further details (accessed 1/05/2009).

TCPA and WWF (Town and Country Planning Association/World Wide Fund for Nature) (2003) Building Sustainably: How to Plan and Construct New Housing for the 21st Century. World Wide Fund for Nature (WWF), Godalming, Surrey. See www.tcpa.org.uk/shf/Buildingsustainably.pdf for further details (accessed 2/05/2009).

WCED (World Commission on Environment and Development) (1987). Our Common Future. Oxford University Press, Oxford.

\section{WHAT DO YOU THINK?}

To discuss this paper, please email up to 500 words to the editor at journals@ice.org.uk. Your contribution will be forwarded to the author(s) for a reply and, if considered appropriate by the editorial panel, will be published as discussion in a future issue of the journal.

Proceedings journals rely entirely on contributions sent in by civil engineering professionals, academics and students. Papers should be $2000-5000$ words long (briefing papers should be 1000-2000 words long), with adequate illustrations and references. You can submit your paper online via www.icevirtuallibrary.com/content/journals, where you will also find detailed author guidelines. 